\title{
A PESSOA COM DEFICIÊNCIA INTELECTUAL E A COMPREENSÃO DE SUA EXISTÊNCIA
}

\author{
The person with intellectual disability and the understanding of their existence
}

La persona con discapacidad intelectual y la comprensión de su existencia.

\begin{abstract}
Resumo: Frequentemente as pessoas com deficiência intelectual (DI) não são reconhecidas como capazes de atribuírem significados a sua existência, por apresentarem uma limitação intelectual. Contudo, elas podem compreender diversas questões psicológicas em sua vida. Embasado na Psicologia Existencial Sartriana, o objetivo deste estudo é investigar como a pessoa com DI compreende sua existência, a partir dos sentidos que atribui a si e as suas relações. O método fenomenológico foi escolhido para a coleta e a análise dos dados. Participaram dez adultos com DI, estudantes de uma Escola Especial de Curitiba. Os resultados evidenciaram sentimentos de solidão e abandono por parte dos participantes, decorrente da ausência afetiva e do diálogo com outras pessoas; a angústia diante da sua liberdade, em um contexto onde não lhes são permitidos fazerem escolhas autênticas; a dificuldade de compreensão de seus sentimentos e o desejo de valorização de suas emoções; a escola como o local onde encontram maiores oportunidades de relacionamentos, mas onde a reflexão sobre as situações cotidianas que vivenciam apresentam-se de modo limitado. Reflete-se que estes aspectos existenciais devem ser considerados nos estudos e nos serviços direcionados às pessoas com DI, para que sua liberdade seja reconhecida, viabilizando a construção de seu projeto existencial.
\end{abstract}

Palavras-chave: Deficiência intelectual; Psicologia existencial; Relações interpessoais.

\begin{abstract}
Often people with intellectual disabilities (ID) are not recognised as capable of attributing meanings to their existence because they have an intellectual limitation. However, they can understand various psychological issues in their lives. Based on the Sartrian existential psychology, the objective of this study is to investigate how the person with ID understands his/her existence, from the meanings they attribute to themselves and their relationships. The phenomenological method was chosen for data collection and analysis. Ten adults with ID participated, students of a Special School in Curitiba. The results showed feelings of loneliness and abandonment on the part of the participants, resulting from absence of affect and dialogue with others; the anguish before their freedom, in a context where they are not allowed to make authentic choices; the difficulty of understanding their feelings, and the desire to value their emotions; the school as the place where they find greatest opportunities for relationships, but where reflection on the everyday situations they experience is limited. It is argued that these existential aspects must be considered in the studies and services directed to people with ID, so that their freedom is recognized, enabling the construction of their existential project.
\end{abstract}

Keywords: Intellectual disability; Existential psychology; Interpersonal relations.

Resumen: A menudo las personas con discapacidad intelectual (DI) no son reconocidas como capaces de atribuir significados a su existencia por su limitación intelectual. Sin embargo, pueden comprender diversas cuestiones psicológicas en su vida. Basado en la Psicología existencial Sartriana, el objetivo de este estudio es investigar cómo la persona con DI comprende su existencia, a partir de los sentidos que se atribuye a sí mismo y sus relaciones, por medio del el método fenomenológico. Participaron diez adultos con DI, estudiantes de una escuela especial de Curitiba. Los resultados evidenciaron sentimientos de soledad y abandono por parte de los participantes, resultante de la ausencia afectiva y del diálogo con otras personas; la angustia ante su libertad, en un contexto donde no se les permite hacer elecciones auténticas; la dificultad de comprender sus sentimientos y el deseo de valorar sus emociones; la escuela como el lugar donde encuentran mayores oportunidades de relaciones, pero donde la reflexión sobre las situaciones cotidianas que experimentan se presentan de modo limitado. Se refleja que estos aspectos existenciales deben ser considerados en los estudios y en los servicios dirigidos a las mismas, para que su libertad sea reconocida, permitiendo la construcción de su proyecto existencial.

Palabras- clave: Discapacidad intelectual; Psicología existencial; Relaciones interpersonales.

\section{Introdução}

Durante um período na história da humanidade, em diferentes culturas, a deficiência intelectual (DI) foi compreendida como a perda da racionalidade. Por este motivo, as pessoas com deficiência não eram reconhecidas como plenamente humanas, sendo marginalizadas e excluídas dos diferentes contextos sociais (Pessotti, 1984). Com o predomínio da ciência positivista sobre o conhecimento, a deficiência passou a ser concebida como uma doença, sendo definida principalmente a partir da dimensão 
biológica e organicista da inteligência, com enfoque no déficit intelectual (Bianchetti, 2004). Apesar da manutenção de preconceitos, estereótipos e estigmas, outros sentidos foram sendo produzidos sobre a DI pelos estudiosos do tema e pelas próprias pessoas com deficiência que passaram a questionar uma definição baseada unicamente na dimensão biológica da deficiência. Além desse critério, as definições atuais consideram que os contextos nos quais a pessoa com DI vive, bem como a identificação e o provimento sistemático dos apoios de que necessita, são capazes de contribuir para o seu desenvolvimento, aprendizagem, qualidade de vida, bem-estar e participação social. Esta perspectiva possibilita a identificação e eliminação das barreiras físicas e atitudinais que impedem ou dificultam o desempenho de seus papéis sociais e do exercício de seus direitos, promovendo mudanças para que elas possam se incluir efetivamente em todas as áreas sociais. A partir desta concepção, a DI passa a ser entendida como um estado particular de funcionamento que começa na infância, é multidimensional, e é transformada positivamente pelos apoios individualizados, não sendo, portanto, uma condição estática e permanente. (AAIDD, 2010).

Acompanhando a historicidade do reconhecimento das possibilidades de desenvolvimento de pessoas com DI, identificase um aumento no número de estudos científicos sobre os aspectos médicos, educacionais, políticos e culturais que perpassam a questão, mas os aspectos subjetivos - o que estas pessoas sentem, vivenciam, querem e desejam - são pouco considerados. Grande parte dos estudos são teóricos ou realizados com os familiares e profissionais que atendem estas pessoas (Garcia, 2012). Estudos com as próprias pessoas com DI vêm sendo desenvolvidos em várias partes do mundo, mas no Brasil ainda são escassos. Além disso, há uma proeminência de temas de pesquisa relacionados à educação e ou à escolarização da pessoa com DI, evidenciando uma lacuna quanto a trabalhos que considerem as emoções destas pessoas e sua participação na interpretação dos resultados das pesquisas, prática comum em outros países (Souza \& Barbato, 2017). Estudos sobre a qualidade de vida destas pessoas, que envolvem aspectos subjetivos, também são raros na realidade brasileira (Pereira, 2009). Desde as últimas décadas, vem ganhando espaço na produção acadêmica uma linha de investigação voltada para a auto percepção das pessoas com deficiência, significando um avanço na área, pois, até então, as percepções destas pessoas raramente eram levadas em consideração na elaboração das teorias sobre a deficiência e no planejamento e implementação de programas de atendimento (Glat \& Pletsch, 2009). Contudo, especificamente os estudos com pessoas com DI ainda são raros, pois devido ao estigma de DI estas pessoas não são reconhecidas como capazes de refletir, analisar, opinar e tomar decisões a respeito de sua própria vida (Glat, 1999).

Com base no estigma de DI a sociedade, e alguns profissionais e familiares envolvidos com esse grupo, frequentemente não acredita que a pessoa com DI pode, como qualquer outro ser humano, ter angústias, dificuldades emocionais, ser capaz de expressar seus sentimentos e compreender seus desejos e necessidades. É como se apresentassem uma existência incompleta por terem uma limitação em seu intelecto (Glat, 1999). Contudo, diferentes estudos evidenciam que estas pessoas são capazes de expressar seus sentimentos e podem não apenas falar, mas também compreender, com apoio familiar e educacional adequado, as diversas questões psicológicas presentes em sua vida (Garcia, 2012). Para tanto, é fundamental o reconhecimento da potencialidade destas pessoas para expressarem por si mesmas suas (in)satisfações com oportunidade de conduzirem seu próprio processo de desenvolvimento, fazendo escolhas e tomando decisões que sejam importantes para elas (Pereira, 2009). Estudos têm demonstrado que as pessoas com DI são mais vulneráveis a situações de estresse que a população em geral em decorrência de receberem menos apoio emocional e terem uma baixa convicção nas suas próprias habilidades (Lunsky, 2008). No campo da saúde mental, a literatura estima que cerca de $40 \%$ das pessoas com DI têm associados diagnósticos de transtornos mentais e/ou comportamentais, mas esse avanço não é perceptível em relação aos serviços na área da saúde mental oferecidas a estas pessoas (Surjos \& Campos, 2013). O reconhecimento da vulnerabilidade desta população no campo da saúde mental é essencial para assegurar um cuidado integral e adequado a ela (Tomaz, Rosa, Van \& Melo, 2016).

No campo científico existem importantes desafios para a investigação psicológica com pessoas com DI, perpassando por questões práticas e éticas como: onde encontrar os indivíduos participantes da pesquisa (em contextos muito específicos, como escolas especiais); a quem solicitar a autorização para a participação desses adultos nas pesquisas empíricas (aos cuidadores exclusivamente ou àqueles que serão parceiros na construção do conhecimento); que instrumentos utilizar para a interação com os adultos com DI, notadamente quando os processos comunicacionais forem qualitativamente diferenciados; como conduzir análises que confiram papel ativo a esses adultos em seu desenvolvimento (Wanderer \& Pedroza, 2013). Diante desta realidade, destaca-se a relevância e a necessidade de estudos que se preocupem em compreender a vivência das próprias pessoas consideradas DI para que se efetivem medidas concretas que atendam às suas necessidades no campo da saúde, da educação, do trabalho, do lazer, da cultura, e outros âmbitos, 
reconhecendo a igualdade de direitos a todas as pessoas.

Desse modo, ancorado na Psicologia Existencial Sartriana, este estudo tem como objetivo investigar como a pessoa com DI compreende sua existência, a partir dos sentidos que atribui a si e as suas relações. Para tanto, considera-se necessário apresentar alguns pressupostos teóricos desta perspectiva, relacionando com a DI.

\section{Deficiência intelectual e Psicologia Existencial Sartriana}

As abordagens existenciais no campo da psicologia postulam que a existência do sujeito se define a partir da compreensão que ele tem de suas experiências que resultam na descoberta de si mesmo (Teixeira, 2006). Para Sartre o sujeito é livre e constrói sua dinâmica psíquica a partir das condições materiais e sociais concretas, mas com capacidade de transcender esta realidade, não sendo determinado por ela. A liberdade, que se apresenta como ação no mundo, exige posição constante do sujeito perante a realidade social. A partir da combinação dos dados de sua realidade e de suas possibilidades o sujeito realiza escolhas que resultam no reconhecimento de si como aquele que realizou tais ações, que teve tais emoções, que é esta ou aquela pessoa, definindo-se a partir daquilo que projeta no futuro, identificado como "projeto de ser", podendo escolher viver de acordo com os seus valores mais profundos no seu comprometimento familiar, profissional e comunitário (Schneider, 2011). Desse modo é no processo de apropriação das condições materiais, sociais, familiares e existenciais concretas que o sujeito constitui sua subjetividade, que imediatamente se objetiva através de seus atos, pensamentos e emoção (Perdigão, 1995). O ser humano é resultado do processo de interiorização da exterioridade coletiva e da exteriorização de sua apropriação particular, sendo, por isso, um agente da história individual e coletiva ao realizar uma apropriação particular da realidade coletiva que o cerca, a qual ele mesmo contribui para construir. (Vieira, Ardans-Bonifacino \& Roso, 2016).

Segundo Sartre (1943/2011), o ser humano tem suas vivências no mundo sempre mediadas pelos outros, inclusive na construção de seu projeto existencial. Para o filósofo, o fenômeno de ser visto pelo outro assume importância capital na constituição de uma pessoa, pois sem o olhar do outro ela não se sentiria objetivada e situada em um determinado espaço, existindo concretamente como corpo físico e com possibilidade de refletir sobre quem se é. Com isso, uma pessoa só é capacitada a formular um juízo objetivo sobre ela, reconhecer-se de determinado modo, com determinadas característica e qualidades, porque esse tipo de autoconhecimento passa pelo outro que é o intermediário indispensável que remete a ela mesma. Nesta dinâmica, uma pessoa pode reconhecer a outra como alguém livre e aberta para fazer escolhas autênticas, possibilitando seu crescimento existencial, participando da construção de seu projeto, ou pode reconhecer a outra pessoa como desprovida de um projeto existencial. $\mathrm{Na}$ última situação, a objetividade é experimentada como "alienação" onde a pessoa procura fazer escolhas a partir do ponto de vista do outro. Sua liberdade é transformada em fixidez, pois o outro designa-a dessa ou daquela maneira, suprimindo suas potencialidades e seu crescimento existencial.

A partir destes fundamentos, pode-se compreender a deficiência como produto direto da relação que se estabelece entre as pessoas com deficiência e outros membros majoritários do grupo social a que pertencem e que as reconhecem e as tratam como tal. De acordo com Goffman (1988), o padrão de relacionamento entre as pessoas se baseia em estereótipos, pois ao interagir com alguém, acessam-se inúmeras vivências a ele relacionado. $\mathrm{Na}$ sociedade existe uma rede de critérios interiorizados baseada nos valores e costumes adotados em uma determinada época. Ao olhar algo imediata e inevitavelmente o indivíduo utiliza esses critérios para determinar se o foco de seu olhar é ou não desviante dos padrões culturalmente aceitos. No caso das pessoas com deficiência, o estigma de deficiente se interpõe em todas as relações como um construto social que é internalizado pela maioria das pessoas como coisa anormal. Com base nisso, as pessoas fazem vários tipos de discriminação, através das quais efetivamente e, muitas vezes sem pensar, acabam excluindo as pessoas com deficiência de diferentes contextos. Desse modo, segundo Erthal (1990), apesar da essência da liberdade ser a escolha existem condições psicológicas, biológicas, sociais, as quais o homem acaba por ter que se submeter já que não é um ser isolado, originando os conflitos que o indivíduo encontra em seu meio social. Considerando o significado atribuído à deficiência, pode-se dizer que as maiores condições que limitam a liberdade da pessoa com DI não é sua limitação cognitiva, mas as barreiras que a própria sociedade impõe a esses sujeitos, que se traduzem em atitudes preconceituosas e de exclusão. De acordo com Glat (1999), no campo das relações sociais, uma ideia equivocada é que a de que uma pessoa com DI não tem interesse ou habilidade para se incluir na sociedade. Entretanto, se algumas destas pessoas demonstram um nível mais baixo de autonomia e inserção social é por terem sido tratadas a vida toda como independentes e incapazes de participar do convívio social.

Para a Psicologia Existencial, há por parte da pessoa a escolha da aceitação da objetivação imposta pelo outro, ou a possibilidade de escolher ser diferente daquilo que os outros esperam dela, caso isto não esteja de acordo com seu projeto existencial. Por isso, a pessoa com DI mesmo 
vivendo em uma sociedade que frequentemente a coloca como incapaz, pode tornar-se consciente da responsabilidade que tem sobre suas escolhas e desenvolver uma compreensão do que tem sido e de suas possibilidades e limitações. Essa liberdade e responsabilidade é possível por que, de acordo com Perdigão (1995), ser realmente livre não é obter-se necessariamente do que se quer, mas determinar-se a querer por si mesmo, pois a liberdade humana está na autonomia da escolha. $\mathrm{O}$ homem não escolhe a situação, mas pode eleger sua atitude em face do que faz dessa condição, pois o importante é o que o sujeito faz daquilo que foi feito a ele. O projeto de cada pessoa é único, próprio, singular e se realiza em uma ação prática igualmente única.

Nesse sentido, as pessoas com DI precisam ser reconhecidas pela sociedade como sujeitos que têm vontades e desejos, sendo oferecidas a elas apoios necessários em cada fase de seu desenvolvimento, de acordo com sua realidade existencial, modificando o olhar deindiferençaecompreendendoasingularidade de cada ação humana que revela a liberdade do outro que deve ser respeitada, independente de seus atributos. Schneider (2011) afirma que há para Sartre uma estrutura possível na relação com o outro que implica o "nós". Neste caso, ser-com-o-outro significa compartilhar projetos, dividir situações, tomar decisões conjuntas, buscando a reciprocidade e o reconhecimento do outro enquanto liberdade, que viabiliza a construção de seu projeto existencial. Com este objetivo, segundo Schneider (2011), Sartre compreende que as relações afetivas que o homem estabelece com os outros que lhe são significativos não são meras relações sociais, onde a pessoa participa de certos grupos, relaciona-se com diversas pessoas, cumpre papéis e funções sociais, mas são relações que comprometem seu ser, definem seu espaço, constituem sua subjetividade. Esta dimensão relacional envolve as atitudes e os sentimentos de uma pessoa em relação a outra, tais como amor/ ódio, aceitação/rejeição, partilha/isolamento, e inclui também os significados que os outros têm para a própria pessoa, quer sejam os familiares, os amigos e demais pessoas de seu círculo social. A compreensão de uma pessoa sobre sua existência é construída neste contexto de relações afetivas.

\section{Metodologia}

O método fenomenológico foi escolhido para conduzir esta pesquisa por ser um recurso apropriado para pesquisar a vivência e os sentidos que os sujeitos atribuem às suas experiências, ao ser dirigido para as percepções que os sujeitos têm daquilo que está sendo pesquisado, as quais são expressas por ele mesmo (Martins \& Bicudo, 1994), revelando-se adequado ao objetivo desse estudo de investigar como a pessoa com DI compreende sua existência, a partir dos sentidos que atribui a si e às suas relações.

\section{Participantes}

Dez pessoas adultas com diagnóstico de DI estudantes de uma escola na modalidade de educação especial da cidade de Curitiba - PR participaram do presente estudo. O grupo foi composto por seis mulheres e quatro homens. Com exceção de uma participante com quarenta e três anos, os outros participantes situavam-se com idade média de vinte e cinco anos. Todos os participantes moravam com seus familiares: pais, irmãos, cunhado ou tios. Por uma questão ética foram utilizados pseudônimos para nomear os participantes da pesquisa, bem como as demais pessoas citadas nas falas dos participantes. Ressalta-se que um participante trabalhava como empacotador em um supermercado, os demais eram apenas estudantes.

\section{Procedimentos e instrumentos}

A pesquisa foi realizada em uma Escola na Modalidade de Educação Especial de Curitiba, Paraná, onde um dos pesquisadores trabalhava como psicólogo. A escola atende pessoas com DI a partir dos quinze anos de idade. Foi apresentada a proposta do estudo para a equipe diretiva e após a aprovação pela instituição foi feita uma lista de todos os alunos que preenchiam dois critérios de inclusão: (a) facilidade de comunicação e entendimento das questões, uma vez que a coleta de dados era feita por meio de entrevista gravada; (b) o interesse e a motivação em participar da pesquisa. Um termo de consentimento livre e esclarecido, com explicações detalhadas da pesquisa, foi enviado aos responsáveis de todos alunos com base na lista criada, por meio da agenda escolar dos estudantes. O pesquisador se colocou à disposição para esclarecer todas as dúvidas dos responsáveis. De quarenta e oito termos enviados, apenas retornaram dez assinados. Após a aprovação dos familiares e do consentimento pessoal dos participantes, que também assinaram o termo (os não alfabetizados colocaram suas digitais), as entrevistas foram agendadas e realizadas na própria escola.

As entrevistas, com duração mínima de trinta minutos, foram feitas de forma individual em uma sala apropriada para conservar a intimidade dos participantes e para que eles se sentissem à vontade em responder as perguntas. Estavam presente apenas o pesquisador e o (a) entrevistado (a). Inicialmente, o pesquisador explicava o objetivo da pesquisa aos participantes que foram informados que a conversa seria gravada, mas que seus depoimentos e identidades não seriam divulgados. Essas informações foram dadas em uma linguagem simples e objetiva, as eventuais perguntas dos participantes foram respondidas. Os limites dos participantes foram respeitados para não os constranger, cabendo a eles responderem apenas ao que tivessem vontade.

Em um primeiro momento foi pedido aos participantes que de forma livre falassem sobre eles. 
A questão inicial foi “fale sobre você". Posteriormente, foi acrescentada a pergunta "como você se relaciona com as pessoas? ”. Com base na fala dos participantes, outras questões eram colocadas pelo pesquisador aos entrevistados de modo a clarificar e aprofundar suas compreensões. De acordo com Amatuzzi (2011), a possibilidade do pesquisador atuar como facilitador do acesso ao vivido é de fundamental importância na pesquisa fenomenológica, pois, muitas vezes, os participantes nunca tiveram oportunidade de efetivamente falar sobre sua experiência, sendo no ato da relação pessoal, quando surge a oportunidade de dizê-lo, que tal conteúdo é acessado.

\section{Análise dos dados}

As entrevistas, gravadas e transcritas integralmente, foram analisadas de acordo com as premissas do método fenomenológico realizado em quatro momentos 1) Leitura geral da entrevista, sem interpretações, buscando familiarização com o fenômeno; 2) Identificação de unidades de significado, focalizando o fenômeno estudado, no caso a compreensão que a pessoa com DI tinha de sua existência; 3) Releitura dos textos na procura de apreensão mais abrangente do fenômeno estudado; 4) Reagrupamento dos elementos relevantes, transformando as unidades de significado em uma descrição consistente da estrutura do fenômeno, com base nas convergências dos discursos, naquilo que permaneceu de algum modo em todos os relatos e que, portanto, aponta para essência do fenômeno estudado (Martins \& Bicudo, 1994).

\section{Resultados e Discussão}

Os resultados foram agrupados em três unidades de significado: "o (não) falar sobre si e o sentimento de solidão e abandono”; "a percepção de si e a angústia existencial”, "a escola como espaço de convivência e relações significativas”.

O (não) falar sobre si e o sentimento de solidão e abandono

Ao serem solicitados a falar sobre si, incialmente o silêncio dos participantes se fazia presente. Como disseram: "Eu falo de mim só quando alguém pergunta, ou então não falo. Só falo quando alguém quer saber alguma coisa de mim, pois não tenho o que dizer” (Álvaro). "Eu gosto de falar sobre mim, mas é difícil, só falo quando alguém pergunta. Se não perguntar, não falo” (Felipe). Dessa forma, compreendeu-se que estas pessoas falam de si apenas quando há interesse por parte de outras pessoas, o que normalmente não acontece, pois, segundo os participantes: "Conversar eu não converso muito, eu fico quieto no meu canto, eu não tenho ninguém para conversar, ninguém quer conversar comigo" (Leonardo). "Eu não tenho coragem de falar de mim para as pessoas, eu acho que elas não querem me ouvir, porque fogem de mim, se eu falo algo elas não querem nem escutar” (Marcela).
Nesse sentido, a conversa, que parte então sempre do outro, torna-se restrita a questões em torno das atividades do dia-a-dia: "Eu falo do futebol que eles (pais) perguntam para mim (...). Eles perguntam como eu estou na escola. As outras pessoas perguntam como estou em casa, perguntam se minha família vai bem" (Álvaro). "Converso com a minha avó, com minha tia, falo que eu gosto de ir à igreja, que eu gosto de ir à escola, essas coisas" (Julia). "Falo se estou estudando, converso com eles (familiares) sobre como estão as coisas". (Dione). Assim, conversar para essas pessoas significa falar sobre "como estão as coisas", no entanto, não contam, por exemplo, como elas se sentem em relação ao que vivenciam. Não se aprofundam em seus diálogos e nas questões mais pessoais que experimentam, como seus conflitos e angústias:

"Eu não gosto de falar para eles (família) que estou triste, eu vou falar pra Deus (...) a única pessoa com quem eu comento sobre o que sinto é com Jesus. Agora os outros assim não. Porque Jesus é meu melhor amigo." (Julia).

"Aquele dia que o pai estava ruim eu pensei que ele estava morrendo né? Me deu aquela sensação, aquele aperto, e daí começa a doer o peito né? E eu pensei o pai vai embora né? Parecia que as três noites que o pai estava no hospital, as três noites parecia que ele estava indo embora. E eu não comentei disso com ninguém e ninguém me perguntou”. (Lílian)

Para o existencialismo sartreano, é por meio de uma consciência reflexiva que um sujeito pode compreender suas ações e sentimentos, pois é espontaneamente afetado pelas situações que vivencia. Sartre (1939/2014, p.55) afirma que "é sempre possível tomar consciência da emoção como estrutura afetiva da consciência, dizer: estou com raiva, tenho medo, etc”, pois a emoção é uma certa maneira de compreender o mundo. As coisas adquirem significado conforme a situação em que se está inserido e implicam na experimentação que dela se tem. Portanto, o confronto com as emoções e os próprios sentimentos são necessários para o desenvolvimento do "projeto existencial" do sujeito (Sartre, 1939/2014).

$\mathrm{Na}$ fala dos participantes, observou-se que raramente é dada oportunidade e possibilidade para eles se expressarem. A pouca possibilidade de compartilhar sua vida emocional com outras pessoas favorece o sentimento de solidão que se revelou nos relatos de vida das pessoas com DI:

É ruim ficar sozinha! Eu fico triste às vezes, eu choro, não gosto de ficar sozinha. Como aqui no recreio da escola, fico do meio-dia até a hora de entrar na sala sozinha porque ninguém conversa comigo! Eu fico sozinha e eu não 
gosto de ficar sozinha. Com a família eu me sinto bastante sozinha, com os amigos a mesma coisa, eu me sinto sozinha na igreja também. Eu não quero ficar sozinha! É ruim! Eu não gosto de ficar sozinha. (Julia)

O sentimento de solidão, abandono e tristeza, marca a fala de Júlia e esteve presente na fala de outros participantes. Nesse sentido, a tristeza decorre da ausência, nem sempre física, pois o sentimento de ser sozinha apareceu mesmo em meio a muitas pessoas, mas principalmente interna, consciente da ausência do outro. Os participantes da pesquisa demonstraram o quanto é difícil não ter alguém que os escute e os entenda. Em muitos momentos, estas pessoas não se sentem vistas e importantes para alguém. O sentimento de solidão surge como resultado da distância afetiva das outras pessoas. Tem-se então o desejo de alguém que goste delas como pessoas únicas e com quem podem conversar para não se sentirem tão sozinhas: "Se alguém se importasse comigo eu não estava desse jeito, triste, magoada com o coração apertado e doendo (...) eu queria que falassem mais comigo, mas ninguém conversa comigo”. (Camila). Amanda, outra participante, também relata:

A Roberta era a moça que cuidava do pátio no intervalo (...) às vezes eu estava sozinha e triste em um canto e a Roberta me chamava para conversar, a gente conversava bastante (...) ela queria saber o que eu estava sentindo sabe? (...) Eu me sentia alegre quando ela estava comigo, depois ela foi embora da escola e eu senti muita falta dela, ficou sem graça, ninguém mais conversa comigo."

Para a Psicologia Existencial, conforme Camon (2002), a solidão é condição imanente ao homem e faz parte de sua vida, porém, em determinados momentos, as pessoas a percebem mais agudamente e não sabem, ou tem dificuldade, em lidar com este sentimento. A solidão - ser só - é diferente de isolamento - estar só. O isolamento social se revela presente na vida das pessoas com DI e tem origem a partir do modo superficial com que as pessoas em geral se relacionam com elas, isso torna muito penosa a sensação de ser só que se revela forte e dolorida. Ao se relacionar com alguém íntimo, a sensação que uma pessoa tem é de que a solidão se afasta de sua existência. Por isso, quando uma pessoa procura outra é para que, ainda que por breves momentos, ela possa ter significado para alguém. Se o outro de alguma forma a percebe e ama, ameniza o peso da solidão na convivência e na interação com esse outro.

\section{A percepção de si e a angústia existencial}

$\mathrm{Na}$ perspectiva existencial o autoconceito é a visão que uma pessoa tem de si própria baseada em experiências passadas, estimulações presentes e expectativas futuras. Apresenta dois aspectos: a maneira como o indivíduo encara suas capacidades, status e papéis sociais; e o que ele gostaria de ser, suas aspirações, ou autoimagem idealizada. (Erthal, 1990). Em relação à forma como se vêem os participantes desta pesquisa definiram-se em termos gerais como "educados", "prestativos", "inteligentes", "esforçados", "comportados", "calmos", "estudiosos”. Percebeu-se que ao falarem de si enfatizavam principalmente seus aspectos positivos: "Ah eu gosto de mim, eu sou uma pessoa legal, simpática, educada, gosto de ajudar, conversar com os colegas e ajudar os professores" (Marcela). No entanto, em alguns momentos, estas pessoas demonstraram o quanto é difícil lidar com a forma como os outros as vêem, que nem sempre corresponde a essa imagem que têm de si e que revela outros aspectos, não agradáveis de sua existência. Os próprios colegas apontam aquilo que em muitos momentos essas pessoas não aceitam em si mesmo: "Ontem eu fui trabalhar na horta e a Carla me chamou de feia, de bruxa, chata, nervosa, daí eu falei: - Não sou bruxa sou uma pessoa legal e não gosto que me chamem de bruxa" (Lúcia). "Eu me sinto feio, me acho feio, é difícil uma pessoa achar que eu sou bonito, então eu me acho feio mesmo!" (Felipe).

Os adjetivos que qualificam as características que constituem o autoconceito formam o sentimento de autoestima, extensão na qual o indivíduo admira ou valoriza o eu. O olhar do outro interfere na autoimagem que tem relação com o esquema corporal e envolve a autoestima e autoavaliação. A autoestima é, em parte, determinada pelas experiências anteriores da pessoa tal como ela percebe, pois existem aquelas que apesar de suas qualidades tende a percebê-las como nulas ou deficientes. O que parece ser o caso dos participantes deste estudo que se definem de modo positivo, mas que pelo olhar do outro, nas situações reveladas pelas suas falas, sentem o oposto disso e revelam uma imagem de si negativa, e, consequentemente, baixa autoestima (Erthal, 1990).

Segundo Bianchetti (2004), na contemporaneidade, a diferença, ou deficiência, é apreendida como defeito. O que se busca, a todo custo, é a padronização, obedecendo a critérios que só são preenchidos por uma minoria No caso da pessoa com deficiência, o outro pode colocála como incapaz, diferente, prendendo-se ao estereótipo, estigmatizando-a. Para o outro ela será "inútil”, “feia”, “anormal”. Por outro lado, a pessoa com deficiência assume essa imagem para si e, presa a isso, pode deixar de conhecer determinados os aspectos de sua existência. Para Sartre (1943/2011), a liberdade de escolha consiste na principal característica da condição humana e vem acompanhada da responsabilidade do sujeito assumir e se responsabilizar pelas suas escolhas. Porém, a angústia resultante dessa responsabilidade 
pode tornar-se um fardo pesado demais, tendo em vista as possibilidades barradas no cotidiano ou mesmo a dificuldade em compartilhar essa angústia. Sartre chama de má-fé o ato do sujeito assumir espontaneamente uma identidade rígida, a ponto de negar que exista uma possibilidade de ser diferente. Trata-se de uma imagem fixa que o sujeito criou de si mesmo ou de algum papel social que desempenha, com o objetivo de aliviar seu sentimento de angústia.

Quando as outras pessoas não se relacionam do modo como a pessoa com DI espera ser tratada, ela sente como se as outras pessoas não gostassem dela: "Eu não gosto de ser maltratada (...) maltratada é quando as pessoas saem correndo da gente (...) qualquer brincadeira que as pessoas fazem comigo me deixam nervosa, brincadeiras tipo: a Lúcia é uma feia, uma bruxa”. (Lúcia). “Ah, a pessoa precisa aprender a aceitar a gente assim né? A não brigar com a gente e a ajudar quando a gente precisar também. Tem que gostar da gente”. (Júlia). Estas afirmações parecem revelar não apenas a necessidade de relacionamentos onde sentimentos amorosos de consideração e respeito estejam presentes, mas também as dificuldades em elaborar os próprios sentimentos socialmente considerados negativos como raiva e vergonha. O pensar sobre si próprio e os sentimentos que derivam desta reflexão estão articulados com as oportunidades de vivenciar relações sociais que confirmam ou alteram aquilo já anteriormente construído através de vivências prévias. A pessoa com DI, como qualquer pessoa, ao compreender a imagem que tem de si, precisa conscientizar-se de suas possibilidades e limitações, reconhecendo tanto seus aspectos positivos como os negativos, criando consigo mesma e com os outros uma relação mais agradável.

A escola como espaço de convivência e relações significativas.

Ao falarem sobre seus relacionamentos com as outras pessoas os participantes do estudo trouxeram suas vivências no contexto escolar. A escola se revelou para eles como o local em que encontram maiores oportunidades de convivência social, aprendendo a fazer escolhas afetivas através de amizades construídas. Fora dela poucos são os contatos com outras pessoas que não sejam de sua família. Em relação aos locais que frequentavam, estes se restringiam a áreas dentro da vizinhança onde são conhecidos, na igreja, e, às vezes, na casa dos colegas.

Desse modo, o sentido que essas pessoas atribuíram a escola foi de um local que gostavam pela possibilidade de conversarem com os colegas e fazerem amizades: "É legal, eu gosto da escola, eu gosto de conversar com todo mundo aqui na escola. Converso com um, converso com outro, a gente dá risada, mas fora da escola com ninguém” (Dione). "Eu gosto dessa escola, eu gosto de ficar aqui. Gosto das professoras, de todo mundo, porque todos gostam de mim e gostam que eu goste deles". (Camila). O espaço educacional apresentou-se, como um local propício para o compartilhamento das emoções, segredos e descobertas sobre si e os outros. As relações de amizade apareceram como um aspecto importante para as pessoas com DI. Com os amigos elas sentiam-se valorizadas, pois amizade estava ligada a companheirismo, compreensão, apoio: "Amizade é companheirismo, ajudar o outro quando precisa e quando não precisa também, nas coisas boas e nas coisas ruins" (Álvaro). "Amizade é carinho, amor, compreensão. Elas (as amigas) me dão apoio para eu não ficar nervosa, não ficar chorando, não brigar" (Lílian). "Amizade é ficar junto com os outros, tratar as pessoas bem, não falar mal, tudo que as pessoas querem”. (Camila). Compreendeu-se que quando existe uma relação de amizade, alguém com quem podem conversar, estas pessoas sentemse aceitas, compreendidas e estimadas. Por isso, é importante ter um amigo, seja para partilhar suas alegrias ou falar sobre seus problemas: "Eu converso um monte de coisa com as pessoas da escola. É bom falar com eles, eu me sinto feliz, alegre, bem né?" (Felipe). "Eu gosto dos amigos porque a gente pode se abraçar, conversar. É carinho que a gente sente, que eu sinto. Eu gosto disso, gosto que conversem e que façam amizade comigo, me deem carinho". (Marcela).

A compreensão de amizade por parte dos participantes evidencia que estas pessoas valorizam na relação com o outro o respeito, a aceitação da diferença, a bondade, o auxílio, a sinceridade. Ao mesmo tempo, esses valores parecem revelar o que eles desejam e esperam por parte das outras pessoas para serem mais felizes em seus relacionamentos. Estas compreensões permitem identificar que as relações sociais da pessoa com DI, apesar de serem restritas a contextos institucionais bem estruturados como a escola e a igreja, podem propiciar a importante experiência de lidar com as próprias limitações e qualidades e reconhecer estes aspectos nos outros. Uma vez que tais limitações são incluídas na relação e as qualidades são ressaltadas, as relações de amizade facilitam a melhoria da autoestima, promovendo a percepção de si enquanto uma pessoa pertencente a um determinado contexto.

Diante destes resultados, é relevante discutir o papel que a escola vem desempenhando em relação as pessoas com DI jovens e adultas. Se esta instituição é um espaço significativo de trocas afetivas com outras pessoas, é também um ambiente que limita a vivência dessas pessoas na sociedade. A terminalidade dos estudos, a inserção no mercado de trabalho e a inclusão em outros contextos extra escolares, não se evidenciou na fala dos participantes. A escola favorece o sentimento de proteção e segurança dos participantes, sendo um local para permanecerem para sempre. Mesmo o participante que trabalhava e tinha autonomia e independência, 
optou por continuar na escola pelo sentimento de pertencimento a este local. Santos, Mendonça e Oliveira (2014) discutem que, apesar das políticas públicas de educação inclusiva, ainda há um número significativo de alunos com DI matriculados em instituições especializadas e classes especiais. As autoras ressaltam que a permanência do estudante com DI somente na instituição especializada acaba por reforçar o estigma da diferença e o sentimento de menos valia, fazendo com que eles não avancem em seu processo de desenvolvimento. Além disso, alguns estudos na área da educação especial apontam que parte dos trabalhos pedagógicos, direcionados a alunos com DI, parecem estar centrados nas incapacidades do sujeito e na imutabilidade da deficiência, evidenciando um desconhecimento do papel da instituição especializada em tempos de inclusão (Santos, Mendonça e Oliveira, 2014). Por ser o principal espaço de convivência destas pessoas, a escola especial deveria criar propostas que possibilitassem a inclusão delas em outros contextos, sendo a escolarização reconhecida como uma etapa de suas vidas, e não como algo para vida toda. $\mathrm{O}$ foco poderia ser em atividades que promovessem a autonomia e independência da pessoa com DI, oferecendo, por exemplo, um trabalho de orientação profissional e sexual, oficinas de cidadania e participação social, criando espaços de trocas significativas que possibilitassem a compreensão de seus sentimentos e a aprendizagem de habilidades para se inserirem em diferentes contextos, encorajando essas pessoas a pertencerem a outros grupos sociais além do ambiente escolar e familiar.

De acordo como Trentin e Raitz (2018), para as pessoas com deficiência a educação exerce um papel fundamental em sua inserção e permanência no mercado de trabalho. Porém, nessa relação educação/trabalho, torna-se necessário um planejamento de transição para a vida pós-escolar, a qual envolva a escola, a família e o próprio jovem. Considera-se pertinente salientar que a educação não deve se restringir ao preparo das pessoas com deficiência para se adaptarem à sociedade e ao mundo do trabalho, mas também para que possam compreender a realidade que as cerca em sua complexidade e historicidade, atuando em prol de formas mais humanizadas de existência social.

\section{Considerações finais}

Este estudo buscou a compreensão que as próprias PDI têm a respeito das questões que perpassam sua existência. Os resultados evidenciam que elas sentem a necessidade de serem valorizadas e apoiadas na compreensão de seus sentimentos, podendo compartilhar com outras pessoas suas experiências, o que possibilita a construção de seu projeto existencial, o exercício de sua liberdade, o confronto com sua angústia e solidão, e a busca por alternativas existenciais menos tristes e desesperadoras, para que desenvolvam ao máximo suas atitudes e comportamentos de acordo com sua realidade existencial em cada fase da vida.

As instituições educativas têm especial função nesse processo por ser o lugar onde as pessoas com DI encontram maiores oportunidades de vivências sociais e afetivas. Para tanto, as escolas especiais precisam se questionar até que ponto não estão reproduzindo a situação de segregação social, mantendo os adultos com DI em um status infantilizado que não permite o acesso à vida adulta e às relações sociais maduras. Em um ambiente vigiado e protegido, convém discutir quais são as oportunidades oferecidas para que estas pessoas alcancem autonomia e independência necessária para o amadurecimento emocional.

No campo da psicologia os profissionais precisam criar alternativas de atendimentos voltadas para às questões existenciais das pessoas com DI, pois poucos são os serviços psicológicos voltados especificamente à esta população. Como foi observado, e outros estudos na área têm indicado, grande parte destas pessoas podem falar sobre si e ser capaz de expressar seus sentimentos, compreendendo-os.

Este estudo se limitou a pessoas com DI em um contexto educacional bastante específico, que é a escola na modalidade de educação especial. Atualmente estas pessoas estão inseridas em outros contextos escolares, de trabalho, de saúde. Muitas famílias reconhecem as capacidades de seus filhos com DI e buscam alternativas que promovam a sua inclusão social. Portanto, recomenda-se que sejam realizados estudos com esta população em contextos diferenciados, ampliando os resultados apresentados neste texto.

\section{Referências}

Amatuzzi, M. M. (2011). Pesquisa Fenomenológica em Psicologia. In M. A. T. Bruns, \& A. F. Holanda, (Org.). Psicologia e Fenomenologia: reflexões e perspectivas (pp. 17-25). Campinas, SP: Alínea.

American Association on Intellectual and Developmental Disabilities. (2010). Intellectual disability: definition, classification, and systems of supports. Washington, DC: AAIDD.

Bianchetti, L. (2004). Aspectos históricos da compreensão e da educação dos considerados deficientes. In L. Bianchetti, \& I. M. Freire. (Org.). Um olhar sobre a diferença: interação, trabalho e cidadania (pp. 21-51). São Paulo: Papirus.

Camon, V.A. (1999). Solidão: A ausência do Outro. São Paulo: Pioneira.

Erthal, T.S. (1990). Terapia Vivencial. Rio de Janeiro: Vozes. 
Garcia, W. P. (2012). Apontamentos e reflexões sobre a sexualidade da pessoa com deficiência intelectual. Psicologia Argumento, 30 (68), 149-160.

Glat, R. (1999). Refletindo sobre o papel do psicólogo no atendimento ao deficiente mental. PSI - Revista de Psicologia Social e Institucional da Universidade Estadual de Londrina, 1(1). Recuperado de http://www.uel.br/ccb/psicologia/revista/ refletind.htm

Glat, R., \& Pletsch, M. D. (2009). O método de história de vida em pesquisas sobre auto-percepção de pessoas com necessidades educacionais especiais. Revista Educação Especial, 22(34), 139-154.

Goffman, E. (1988). Estigma: Notas sobre a Manipulação da Identidade Deteriorada. (4 ${ }^{\mathrm{a}}$ ed.). Rio de Janeiro: LTC.

Lunsky, Y. (2008). The impact of stress and social support on the mental health of individuals with intellectual disabilities. Salud Pública de México, 50(2), 151-153.

Martins, J., \& Bicudo, M. A. V. (1994). A pesquisa qualitativa em psicologia: fundamentos e recursos básicos. São Paulo: Moraes.

Perdigão, P. (1995). Existência e Liberdade: uma introdução à filosofia de Sartre. Porto Alegre: L\&PM.

Pereira, J. R. T. (2009). Aplicação do questionário de qualidade de vida em pessoas com deficiência intelectual. Psicologia em Pesquisa, 3(1), 59-74.

Pessoti, I. (1984). Deficiência Mental: da Superstição à Ciência. São Paulo: Edusp.

Santos, R., Mendonça, S., \& Oliveira, M. C. (2014). A instituição especializada em tempos de inclusão. Revista Educação Especial, 27 (48), 41-52.

Sartre, J. P. (2011). O ser e o nada: Ensaio de Ontologia Fenomenológica (P. Perdigão, Trad). Petrópolis: Vozes. (Texto original publicado em 1943).

Sartre, J. P. (2014). Esboço para uma teoria das emoções (P. Neves, Trad.). Porto Alegre: L\&PM. (Texto original publicado em 1939).

Schneider, D. R. (2011). Sartre e a Psicologia Clínica. Florianópolis: Editora da UFSC.

Souza, F. R., \& Barbato, S. B. (2017). Revisão sistemática de estudos qualitativos brasileiros com pessoas diagnosticadas como deficientes intelectuais. Interação em Psicologia, 21(1), 66-77.
Surjus, L. T. L. S., \& Campos, R. T. O. (2013). Deficiência Intelectual e Saúde Mental: Quando a Fronteira Vira Território. Rev. Polis e Psique, 3(2), 82-96.

Teixeira, J.A. (2006). Introdução a Psicoterapia Existencial. Análise Psicológica, 3(24), 389-309.

Tomaz, R V. V.; Rosa, T. L.; Van, D. B., \& Melo, D. G. Políticas públicas de saúde para deficientes intelectuais no Brasil: uma revisão integrativa. Ciência e saúde coletiva, 21 (1), 155-172.

Vieira, C. A., Ardans-Bonifacino, H. O., \& Roso, A. (2016). A construção do sujeito na perspectiva de Jean-Paul Sartre. Revista Subjetividades, 16(1), 119-130.

Wanderer, A., \& Pedroza, R. L. S. (2013). Adultos com deficiência na psicologia: desafios para uma investigação psicológica politicamente consciente. Revista Psicologia Política, 13(26), 147-164.

Trentin, V.B., \& Raitz, T.R. (2018). Educação e trabalho: formação profissional para jovens com deficiência intelectual na escola especial. Revista Educação Especial 31(62), 713-726.

Wallisten Passos Garcia, Universidade Federal do Paraná. E-mail: wallistenpg@yahoo.com.br

Ana Paula Almeida de Pereira, Universidade Federal do Paraná
Recebido em 15.07.2019

Aceito em 18.01.2021 